\title{
Research on the Current Situation and Development Approaches of Human Resources Service Industry in Jilin Province
}

\author{
Yue Hao \\ College of Business Administration, Jilin Engineering Normal University, Changchun 130012, \\ China;
}

18792044@qq.com

\begin{abstract}
The development of human resources service industry will not only benefit job opportunities employment rate and the management of the industry in a region, but also help to improve the scale and the structure of modern service industry. It has to be pointed out that Jilin Province, as an underdeveloped part of China has lagged behind other provinces in the development of the industry. The paper dealt with some problems on the basis of an analysis over current situation of human resources service firms, relevant government service departments and industry associations in the province, and offered some proposals from the perspectives of policy stimulation, association functions and company construction, etc.
\end{abstract}

Keywords: Jilin Province; Human resources service industry; Modern service industry

\section{吉林省人力资源服务业的发展现状及途径研究}

\author{
郝 月 \\ （吉林工程技术师范学院 工商管理学院, 吉林 长春 130012)
}

摘要: 人力资源服务业的发展不但可以提高一个地区的就业岗位和就业质量, 促进地区人力资源服务业的整体管理水平, 而且有利于扩大现代服务业的规模, 优化服务业结构。吉林省属于经济欠发达的地区, 人力资源服务业发展滞后, 通过对吉 林省人力资源服务企业、政府人力资源服务机构以及行业协会的现状的分析，挖掘存在的问题，进而从政策鼓励角度、行业 协会作用、企业自身建设等方面提出发展建议。

关键词: 吉林省; 人力资源服务业; 现代服务业

中图分类号: $\mathrm{C965}$ 文献标志码: A

引言

在当今社会，人力资源服务业对于一个地区的发展起到了至关重要的作用。不但可以提高一个地区的 就业岗位和就业质量, 促进本地区的人力资源服务业的整体管理水平, 而且有利于扩大现代服务业的规模, 优化服务业结构, 成为国家或地区新的经济增长点。吉林省属于经济欠发达的地区, 人力资源服务业发展 滞后, 在调结构转方式的经济环境下, 人力资源服务业显得尤其重要, 对促进地区经济发展意义重大。

\section{1 吉林省人力资源服务业的现状}

\section{1 人力资源服务企业的发展}

据调查, 2014 年吉林省人力资源社会保障厅统计共有 144 家正规人力资源服务企业, 在这些企业中, 成立时间最早的是吉林省外国企业服务有限公司，成立于 1991 年 3 月，其它大部分企业成立于 2000 年 以后。这些企业发展速度较快，整体布局是以民营企业为主体。从企业提供的人力资源服务项目上看，90\% 以上的企业都提供人才派遣服务， $80 \%$ 企业提供人事代理及人才培训开发服务， $50 \%$ 左右的企业可以提供 人才招聘、管理咨询和人事外包服务, 极少量的几家企业可以提供人才专业测评和电子化人力资源管理服 
务 $(\mathrm{E}-\mathrm{HR})$ 的企业。

\section{2 政府人力资源服务机构的作用}

吉林省有吉林省人才交流开发中心、长春市人才开发服务中心、吉林省开发区国际人才交流中心、吉 林市人才服务中心、延边州人才服务中心等 50 余家政府人力资源服务机构。这些人力资源服务机构除了 办理本身的行政事务外，大多也提供人才招聘信息、大学生就业信息、人事代理和劳务派遣等服务项目。 其中, 省市级人才服务中心能够提供人才培训服务, 其他的人才交流中心服务项目多是人事代理服务和人 才招聘信息服务。

\section{3 人力资源服务行业协会的发展}

吉林省人才服务协会成立于 2002 年, 隶属于吉林省人力资源和社会保障厅, 是吉林省内唯一的人才 交流服务行业组织。目前, 协会发展团体会员 110 个, 其中高校和科研单位 26 个, 大中型企业 28 个, 省、市、县人才中介机构 56 个。长春市人力资源服务行业协会于 2016 年 5 月正式成立, 已经发展会 员单位 79 家。协会组织对促进长春市人力资源服务行业健康有序发展, 带动吉林省其他全地区人力资源 服务业的规范管理起到积极作用。

\section{2 吉林省人力资源服务业存在的问题}

\section{1 人力资源服务行业相关法律法规的缺失}

近几年, 国家虽然出台了有关服务业的政策, 并多次就人力资源服务业发展提出明确要求, 但多为宏 观部署, 操作性不强。吉林省人才资源服务业产生的时间比较短, 发展缓慢, 市场监管手段还比较单一, 监管能力也比较薄弱, 也缺少相应的行业法律法规, 导致人力资源市场的混乱, 影响了整个行业的发展。

\section{2 人力资源服务行业协作能力有限}

人力资源服务行业的产业链还不成熟, 吉林省人力资 源市场的发展, 要求人力资源服务业形成初级、 中级、高级服务产品在内的结构完善、合理的产业链。但吉林省作为东北老工业基地，目前在人力资源服 务上还处于初级阶段, 整个行业缺少活力, 企业的创新意识比较薄弱。在竞争方面, 吉林省人才资源服务 业处于一个无序竞争、恶性竞争的状态。吉林省人才服务协会在制度上还不够健全, 没有为整个行业营造 良好的氛围。

\section{3 人力资源服务企业发展层次较低}

吉林省人力资源服务企业的整体规模比较小，且多为放养状态，运作模式比较陈旧，企业的内部机构 还不够完善。吉林省整体的人力资源服务产品比较单一, 缺乏专业化、精细化的服务体系。在业态划分方 面也比较粗糙, 没有细致的划分, 服务层次较低。企业内部人员的整体素质水平不高, 专业性人才较少, 缺乏核心竞争力，致使企业在品牌构建以及专业化、国际化发展中比较艰难。

\section{3 促进吉林省人力资源服务业发展的途径}

\section{1 加大政策鼓励扶持行业发展}

吉林省要加大对人力资源服务业的扶持力度，对人力资源服务业提供必要的资金援助，促进资金与人 力资源服务业的项目连接, 引导人才资源服务业的发展。可以实行银行贷款的企业项目, 提供一些优惠的 政策。对人力资源服务业的税收也应实行减免鼓励政策，加速整个行业的发展。完善人力资源服务体系， 能够带动整个地区的经济的发展, 促进吉林省经济的转型。 


\section{2 发挥人力资源服务行业协会的作用}

从人才资源服务行业协会自身发展的角度，应完善组织、监督、沟通和协调等职能。首先，应该完善 整个行业的道德规范。要根据吉林省当地的经济发展状况, 依据国家宏观的法律法规, 制定一些符合当地 发展的人力资源服务业行业的道德规范。

通过制定行业准则、行业道德行为等，促进本地区人力资源服务业健康有序的发展；其次，加强行业 协会之间的协作职能。通过对人力资源人员与企业之间的互动, 共享人力资源服务业的一些情报加强交流, 扩大服务的规模提高服务质量。经常组织培训活动，使人力资源服务人员能够有较高的素质。

\section{3 提高企业自身的管理水平}

吉林省人力资源服务企业应该抓住自身产业的优势，不断提高企业的管理水平，走品牌化的道路，通 过企业的核心文化增强竞争力。随着人才资源服务业的发展, 行业竞争会日益加强, 服务企业要想在这样 的环境下立足就要坚持特色发展, 就要根据客户的不同需求制定不同的方案, 提供差异化的服务。

\section{4 建立相关的法律法规体系}

在贯彻落实国家宏观政策的同时，要研究制定本地区推进人力资源服务业发展的配套政策，制定相关 的法律法规进行规范管理，使整个人力资源服务业更加地合法化，对人力资源服务企业以及服务对象均有 约束力，做到有法可依，为其发展奠定法律的保障。

\section{参考文献:}

[1] 董小华．人力资源服务业发展问题初探 [J]。中国人力资源开发，2013（5）：86-89.

[2] 相玉红, 秦桂莲, 李红侠. 辽宁省人力资源服务业发展现状与存在问题分析及对策 $[\mathrm{J}]$. 辽宁科技学院学报, $2012(2): 45-46$.

［3］姚战琪．我国人力资源服务业发展现状、趋势与政策建议 [J]．经济研究参考，2012（46）：48-53.

[4] 刘天. 大学生创业教育存在的问题及对 策 探 讨 $[J]$. 党史文苑, 2009（12）:71-73.

[5] 周霖, 朱贺玲. 试析我国高校创业教育的主要问题 $[J]$. 现代教育科学, 2010（5）:90-93.

[6] 朱明. 我国大学生创业教育研究综述 $[\mathrm{J}]$. 职业教育研究. 2015(06)

[7] 郭万牛, 杨蓉, 伏永祥. 大学生创业教育对策研究 $[\mathrm{J}]$ ． 江苏高教．2009(01)

[8］李洪否, 韩放. 大学生创业教育 [J]. 企业导报. 2009(11)

[9] 苏益南. 大学生创业环境的结构维度、问题分析及对策研究 $[J]$. 徐州师范大学学报(哲学社会科学版). 2014 (06)

[10] 李莎, 王林雪, 康晓玲. 美、印、日高校创业教育比较及对我国的启示 $[\mathrm{J}]$. 西安电子科技大学学报 (社会科学版). 2015(05)

\section{References:}

[1] Dong Xiaohua.Study on the development of human resources service industry [J]. China Human Resources Development, 2013 (5): 86-89.

[2] Xiang Yuhong, Qin Guilian, Li Hongxia. Study on the present situation and existing problems of Human Resources Service Industry in Liaoning Province [J]. Journal of Liaoning Institute of Science and Technology, 2012 (2): 45-46.

[3] Yao Zhanqi. China's human resources services industry development status, trends and policy recommendations [J]. Economic Research Reference, 2012 (46): 48-53.

[4] Liu Tian. College students' entrepreneurship education problems and countermeasures [J]. Shi Shiwen Court, 2009 (12): 71-73.

[5] Zhou Lin, Zhu Heling. Analysis of the main problems of entrepreneurship education in China 
[J]. Modern Educational Science, 2010 (5): 90-93.

[6] Zhu Ming. Overview of China's entrepreneurial education research [J]. Vocational Education Research 2015 (06)

[7] Guo Wan cattle, Yang Rong, Fu Yongxiang. College students' entrepreneurship education countermeasures [J]. Jiangsu Higher Education. 2009 (01)

[8] Li Honglei, Han Fang. College students' entrepreneurship education [J]. Enterprise Herald. 2009 (11)

[9] Su Yiman.Study on the structural dimension, problem analysis and countermeasure of college students' entrepreneurial environment [J]. Journal of Xuzhou Normal University (Philosophy and Social Sciences Edition)

[10]Li Sha, Wang Linxue, Kang Xiaoling. Comparison of entrepreneurship education in America, India and Japan and its enlightenment to China [J]. Journal of Xidian University (Social Science Edition) 2015 (05) 